\title{
An ultrasensitive human cardiac troponin T graphene screen-printed electrode based on electropolymerized-molecularly imprinted conducting polymer
}

\author{
Bárbara V.M. Silva ${ }^{a}$, Blanca A.G. Rodríguez ${ }^{a}$, Goreti F. Sales ${ }^{\text {b }}$, Maria Del Pilar T. Sotomayor ${ }^{\text {, }}$ \\ Rosa F. Dutra ${ }^{a, *}$ \\ a Biomedical Engineering Laboratory, Federal University of Pernambuco, Recife, Brazil \\ ${ }^{\mathrm{b}}$ BioMark/ISEP, School of Engineering, Polytechnic Institute of Porto, Porto, Portugal \\ ${ }^{\mathrm{c}}$ Chemistry Institute, State University of São Paulo (UNESP), Araraquara, Brazil
}

\section{A R T I C L E I N F O}

\section{Article history:}

Received 30 July 2015

Received in revised form

22 October 2015

Accepted 26 October 2015

Available online 28 October 2015

Keywords:

Cardiac troponin T

Molecularly imprinted polymer

Pyrrole

Acid carboxylic-3-pyrrole

Graphene

Point-of-care testing

\begin{abstract}
A B S T R A C T
A nano-molecularly imprinted polymer (N-MIP) assembled on a screen-printed electrode for the cardiac troponin $\mathrm{T}(\mathrm{cTnT})$ was developed. The biomimetic surface was obtained by a co-polymer matrix assembled on the reduced graphene oxide (RGO) electrode surface. The cTnT active sites were engineered using pyrrole and carboxylated pyrrole that was one-step electropolymerized jointly with cTnT by cyclic voltammetry. The stepwise preparation of the biomimetic surface was characterized by cyclic and differential pulse voltammetries using the ferrocyanide/ferricyanide as redox probe. Structural and morphological characterization was also performed. The optimal relation of pyrrole and pyrrole-3-acid carboxylic to perform the cTnT biomimetic nanosurface was obtained at 1:5 ratio. The analytical performance of CTnT N-MIP performed by differential pulse voltammetry showed a linear range from 0.01 to $0.1 \mathrm{ng} \mathrm{mL}^{-1}(r=0.995, p \ll 0.01)$, with a very low limit of detection $\left(0.006 \mathrm{ng} \mathrm{mL}^{-1}\right)$. The synergic effect of conductive polymer and graphene forming 3D structures of reactive sites resulted in a N-MIP with excellent affinity to cTnT binding $\left(K_{\mathrm{D}}=7.310^{-13} \mathrm{~mol} \mathrm{~L}^{-1}\right)$. The N-MIP proposed is based on a simple method of antibody obtaining with a large potential for point-of-care testing applications.
\end{abstract}

(c) 2015 Elsevier B.V. All rights reserved.

\section{Introduction}

Molecularly imprinted polymer (MIP) is a well-known process that allows the manufacture of biomimetic receptors, which is based on the use of specific polymers with a high chemical stability, easy synthesis and low cost. The selectivity of interactions established between biomimetic and target molecules in MIPs provides an interesting substitute to the natural receptors (Ding and Heiden, 2014). Conventionally, the MIP involves the polymerization of functional monomers in presence of a template, which is removed to form specific polymeric cavities against the template or target analyte. During this process, a number of functional monomers are orderly assembled with their functional groups to build suitable sites within the cavities (Hong et al., 2013). MIPs have been used for molecular recognition systems ranging from small molecules to proteins. However, the tailormade concept of MIPs to protein should be carefully considered

\footnotetext{
*Corresponding author. Fax: +55 8121268000

E-mail address: rosa.dutra@ufpe.br (R.F. Dutra).
}

since that their complex structure and molecular size can influence the sensibility of imprinted sites for recognizing the target molecules (Chen et al., 2014; Rossetti and Qader, 2014).

The bulk polymerization technique is a usual method for MIP obtaining. However, this technique presents some limitations for biomimetic sensor applications due to the difficulty to assembly the MIP composite on the electrode surface, maintaining the binding sites exposure to the target molecules (Soleimani et al., 2013). On the other hand, the removal of the target molecules into a composite is a hard task, mainly when the template is tightly attached to the sensor platform (Ding and Heiden, 2014). Recent strategies using the surface imprinting method for constructing the thin-film of protein MIPs have allowed biomimetic sites on the sensor surface constituting integrated systems of biorecognizing (Moreira et al., 2014). The screen-printed electrodes (SPEs) have been pointed as potential sensor substrates to develop unique systems of disposable MIPs, offering a great potential for point-ofcare testing applications. SPE technology involves a simple and low cost manufacturing, in which processes are based on the ink printing on the solid substrates, enabling the mass production of 
biomimetic sensors.

Recently, some reports have been described for synthesizing the MIP directly on the SPE via surface imprinting method (Prasad et al., 2013; Cabral-Miranda et al., 2014; Moreira et al., 2014). This new approach facilitates an effective extraction of templates, promoting more sensitivity on the biomimetic sensor due to a increase in the rebinding events, besides the electron transfer to be enhanced due to the nearness of the reactive imprinted sites on sensor surface. Although this approach presents several advantages, the sensitivity of biomimetic sensor is compromised by the monomers employed, which can result in a non-conductive imprinted matrix. Conductive polymers have been described for polymeric matrix assembling, such as polypyrrole (PPy) (Nezhadali et al., 2013), polythiophene (Huynh et al., 2013), polyaniline (Xue et al., 2014) and poly-3,4-ethylenedioxythiophene (Granado et al., 2014). Among them, the PPy is an attractive candidate for surface imprinting of the MIP due to the easy electrochemical synthesis, high conductivity and good biocompatibility. Additionally, the use of monomers derivatives of the pyrrole (Py) with organic groups is a good strategy to improve the molecular interaction and selectivity established between template molecules and biomimetic sites (Kim et al., 2015).

Graphene is a two-dimensional carbon network nanomaterial that has been applied on the last few years for transistors, photodetectors and resonators due to its excellent electrical properties. Recent studies have showed improvements on the conductivity of graphene, when is thermal, chemical or electrical reduced to form reduced graphene oxide (RGO). After reduction, the disrupted $\mathrm{sp}^{2}$ bonds of $\mathrm{GO}$ are re-established improving the electronic transfer (Calvo et al., 2015; Cinti et al., 2015). In order to further improve the electronic transfer on the graphene modified electrode, the use of conductive polymers can serve as a strategy. Herein, the synergism between RGO and PPy was used to increase the electron transfer; beside promote more amounts of biomimetic sites due to the nanostructured electrode surface area.

Cardiac troponin $\mathrm{T}$ (cTnT) is a sensitive and specific biomarker for diagnostic of the acute myocardial infarction (AMI), the most frequent cardiovascular disease in emergency department in the worldwide. cTnT ( $37 \mathrm{kDa})$ is released rapidly of the contractile apparatus in cardiac muscle within 2-4 h after AMI onset and can be keep on elevated up to 14 days enabling risk stratify and prognostic of the patients (Thygesen et al., 2012). This work proposed a nanosurface-molecularly imprinted polymer (N-MIP) sensor for cTnT detection based on the electropolymerization of the Py, pyrrole-3-carboxylic acid ( $\mathrm{COOH}-3-\mathrm{Py})$ and pyrrole-2-carboxylic acid (COOH-2-Py) monomers on the RGO modified SPE. Different combinations and ratio of the Py monomers was investigated in order to obtain a sensible thin-film of cTnT MIP. The N-MIP sensor was evaluated by cyclic voltammetry (CV) and differential pulse voltammetry (DPV) techniques and further it was applied for analyze of standard and serum samples.

\section{Materials and methods}

\subsection{Reagents}

Py (98\%), COOH-3-Py ( $>96 \%), \mathrm{COOH}-2-\mathrm{Py}$ ( $>99 \%)$, potassium ferricyanide $\left(\mathrm{K}_{3}\left[\mathrm{Fe}(\mathrm{CN})_{6}\right]\right)$, potassium ferrocyanide $\left(\mathrm{K}_{4}\left[\mathrm{Fe}(\mathrm{CN})_{6}\right]\right)$ and oxalic acid ( $\geq 99 \%$ ) were obtained from Sigma-Aldrich (St. Louis, USA). Lithium perchlorate $\left(\mathrm{LiClO}_{4}\right)$ was acquired from Vetec (Rio de Janeiro, BRA). The cTnT purified from human cardiac muscle tissue was purchased from Calbiochem (Darmstadt, DEU). For the manufacture of the SPE was used the following reagents: graphite powder acquiring from Fluka (St. Louis, USA) and carbon ink (Electrodag PF-407 C) purchasing from Acheson (Port Huron,
USA). Phosphate buffer (PB) $\left(0.05 \mathrm{~mol} \mathrm{~L}^{-1}, \mathrm{pH} 5.8\right)$ was used in all experiments for dilution of the samples. Ultrapure water obtained from a Millipore water purification system (18 M $\Omega$, Milli-Q, Millipore) was utilized in all assays. All chemicals were of analytical grade.

Blood serum samples were collected from patients with AMI who were admitted to the Cardiac Emergency Hospital of Pernambuco-PROCAPE (Recife, BRA). An automatic Elecsys 2010 Immunoassay Analyzer (Roche Diagnostics) was used to quantify cTnT via an electrochemical chemiluminescence immunoassay (ECLIA). Samples were stored at $-20^{\circ} \mathrm{C}$ while not in use during the electrochemical measurements.

\subsection{Synthesis of the RGO}

RGO was synthesized by the method of Hummers and Offerman (1958), this consisted in using a mixture of $3 \mathrm{~g}$ of graphite, $60 \mathrm{~mL}$ of $\mathrm{H}_{2} \mathrm{SO}_{4}$ and $1.5 \mathrm{~g}$ of $\mathrm{NaNO}_{3}$, which was kept in an ice bath under magnetic stirring for $24 \mathrm{~h}$. Subsequently, $7 \mathrm{~g}$ of $\mathrm{KMnO}_{4}$, $60 \mathrm{~mL}$ of $\mathrm{H}_{2} \mathrm{SO}_{4}$, and $1.5 \mathrm{~g}$ of $\mathrm{NaNO}_{3}$ was added. The resulting mixture is maintained at low temperature under stirring for $24 \mathrm{~h}$; after that, this is left to rest for $24 \mathrm{~h}$. The material is washed with water until a $\mathrm{pH} \sim 7$ is reached and was obtained graphene oxide (GO). The reduction of graphene is placed $100 \mathrm{mg}$ of GO powder in an oven at $500{ }^{\circ} \mathrm{C}$ and leave for $5 \mathrm{~min}$, then it is cooled to room temperature, getting RGO powder. Subsequently, a RGO solution was prepared through dispersion of $1 \mathrm{mg}$ of RGO powder in $1 \mathrm{~mL}$ of water.

\subsection{SPE manufacture}

The electrode composition $(\mathrm{w} / \mathrm{w})$ included a carbon ink modified with graphite powder (10\%), which were mixed together during $15 \mathrm{~min}$ and then squeezed on the plastic mask over polyethylene terephthalate rectangular surface to obtain a thin film. It contains a circular working area $(4.0 \mathrm{~mm}$ in diameter) connected to a rectangular area $(2.0 \mathrm{~mm} \times 10.0 \mathrm{~mm})$ that was used as electrical contact. After printing, the electrodes were dried at $60{ }^{\circ} \mathrm{C}$ for 20 min and then the mask was removed.

Prior to use, the surface of the as-prepared SPE was firstly polished during 2 min to obtain an mirror surface and then submitted to an electrochemical pre-treatment by recording 40 cyclic voltammograms between $2.0 \mathrm{~V}$ and $-2.0 \mathrm{~V}$ (vs. $\left.\mathrm{Ag} / \mathrm{AgCl}_{(\mathrm{KCl} \text { sat. })}\right)$ in a $\mathrm{KCl}$ solution $\left(0.1 \mathrm{~mol} \mathrm{~L}^{-1}\right)$ (Alonso-Lomillo et al., 2010). The cleaned SPE surface was modified with $10 \mu \mathrm{L}$ of the RGO solution (1 $\mathrm{mg} \mathrm{mL}^{-1}$ ) and kept at $60{ }^{\circ} \mathrm{C}$ to let solvent evaporate.

\subsection{N-mip construction}

The N-MIP was obtained by electropolymerization using a solution containing the cTnT and functional Py monomers deposited on the RGO modified SPE (Fig. 1). Prior to the electropolymerization, the cTnT $\left(10 \mu \mathrm{g} \mathrm{mL}^{-1}\right)$ was incubated with $0.01 \mathrm{~mol} \mathrm{~L}^{-1}$ of a mixture of Py and functionalized Py monomers during $2 \mathrm{~h}$ at $4{ }^{\circ} \mathrm{C}$. This pre-assembling solution was prepared in order to allow interactions electrostatic between the cTnT and the monomers. The cTnT-monomers solution was electropolymerized on the SPE surface after addition of a $\mathrm{LiClO}_{4}$ solution $\left(0.005 \mathrm{~mol} \mathrm{~L}^{-1}\right)$ prepared in PB (0.01 $\mathrm{mol} \mathrm{L}^{-1}, \mathrm{pH} 5.8$ ). The electropolymerization was performed by 20 cyclic voltammograms in the potential range from 0.8 to $-0.8 \mathrm{~V}$ (vs. $\left.\mathrm{Ag} / \mathrm{AgCl}_{(\mathrm{KCl} \mathrm{sat.})}\right)$ and scan rate of $0.02 \mathrm{~V} \mathrm{~s}^{-1}$. An oxalic acid solution $\left(0.005 \mathrm{~mol} \mathrm{~L}^{-1}\right)$ was dropped on the electropolymerized film in order to remove the cTnT during $10 \mathrm{~h}$ at $4{ }^{\circ} \mathrm{C}$ in a moist chamber. After this step, the SPE was rinsed with ultrapure water and then submitted to electrochemical experiments. A nanosurface non-molecular imprinting polymer modified 


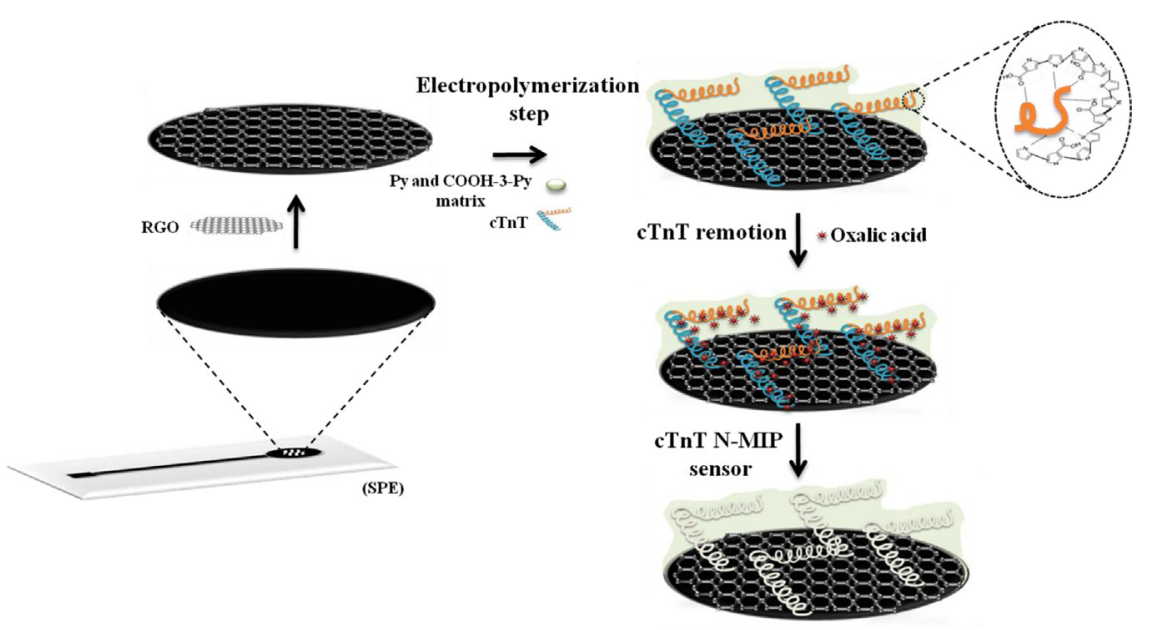

Fig. 1. Stepwise preparation of the biomimetic surface of the N-MIP sensor.

electrode (N-NIP) was prepared as control study. This was synthesized at the same conditions of the N-MIP, except by absence of the $\mathrm{cTnT}$ in the electropolymerization process.

\subsection{Electrochemical measurements}

Electrochemical measurements were performed using the Ivium Compact Stat potentiostat obtained from Ivium Technologies (Eindhoven, NLD) interfaced to a computer system and controlled by Ivium software. An electrode system comprising of the SPE as working electrode, a helical platinum wire as auxiliary electrode and an $\mathrm{Ag} / \mathrm{AgCl}$ (KCl sat.) electrode as reference was employed in all the electrochemical measurements. The stepwise of the N-MIP construction was obtained through the CV and DPV analyses in $\mathrm{K}_{3}\left[\mathrm{Fe}(\mathrm{CN})_{6}\right] / \mathrm{K}_{4}\left[\mathrm{Fe}(\mathrm{CN})_{6}\right]\left(0.005 \mathrm{~mol} \mathrm{~L}^{-1}\right)$ solution prepared in $\mathrm{KCl}\left(0.1 \mathrm{~mol} \mathrm{~L}^{-1}\right)$. CV was scanned in a potential range of $1.0 \mathrm{~V}$ to $-0.6 \mathrm{~V}$, at $0.05 \mathrm{Vs}^{-1}$ scan rate and a step potential of $0.01 \mathrm{~V}$. The DPV was recorded from $0 \mathrm{~V}$ to $0.4 \mathrm{~V}$ with pulse amplitude of $0.05 \mathrm{~V}$, width of $0.05 \mathrm{~s}$ and $0.01 \mathrm{~V}$ step potential. The DPV was also employed to monitore the analytical performance of N-MIP and N-NIP sensor in different cTnT concentrations from phosphate buffer and serum samples.

\subsection{Structural and morphological characterizations}

The morphological characterization of the SPE surface was performed by Scanning Electronic Microscopy (SEM) technique by using a FEI Quanta 200 FEG microscope (Eindhoven, NLD). All the SEM analyses were performed using $20 \mathrm{kV}$ acceleration voltages in low-vacuum mode. Fourier transform infrared (FTIR) spectroscopy spectra were recorded using a Bruker FT-IR Alpha spectrometer Model IFS-66 (Ettlingen, DEU) in attenuated total reflectance (ATR) mode controlled by OPUS software (version 6.5). The analyses were recorded in wavenumber range of $4000-500 \mathrm{~cm}^{-1}$, at room temperature $\left(24 \pm 2{ }^{\circ} \mathrm{C}\right)$ and controlled humidity $(\sim 10 \%)$.

\subsection{Binding isotherm experiments}

The binding properties of the N-MIP and N-NIP were evaluated by calculating the apparent dissociation constant $\left(K_{\mathrm{D}}\right)$ through DPV assays after recorded of analytical curve in different cTnT concentrations. The correlation between the binding capacity of imprinted sites and the cTnT concentrations in solution was performed using the Langmuir isotherm model (Eq. (1)):

$$
I s=\frac{I \max }{1+\left(\frac{\mathrm{KD}}{[s]}\right)}
$$

where $I_{S}$ is the normalized density of the current $\left(\mathrm{A} \mathrm{cm}^{-2}\right) ; S$, the concentration of the cTnT $\left(\mathrm{mol} \mathrm{L}^{-1}\right) ; I_{\max }$, the maximum current density observed $\left(\mathrm{A} \mathrm{cm}^{-2}\right)$ and $K_{\mathrm{D}}$, binding constant $\left(\mathrm{mol} \mathrm{L}^{-1}\right)$ (Moreira et al., 2014).

\section{Results and discussion}

\subsection{Characterization of the nanostructured SPE}

The SEM micrographs were employed to evaluate the morphology of electrode surface. The bare SPE, in Fig. 2a exhibited the presence of several aggregates attributed to the graphite powder $(\sim 100 \mathrm{~nm})$ mixed in the carbon ink. In Fig. 2b, the micrograph of the RGO modified SPE shows superposition of the graphene sheets, in a random distribution that produce a wrinkled surface. The alignment of the RGO is probably due to the van deer Waals interaction between graphene sheets and the carbon sensor surface (Cui et al., 2012).

The functional groups of bare and the RGO modified SPE were evaluated by ATR FTIR spectra (Fig. 2c). In the bare SPE (curve I) was identified the $\mathrm{O}-\mathrm{H}$ stretching vibrations $\left(3300-3500 \mathrm{~cm}^{-1}\right)$, $\mathrm{C}=\mathrm{O}$ vibrations $\left(1720-1740 \mathrm{~cm}^{-1}\right), \mathrm{C}=\mathrm{C}$ from $\mathrm{sp}^{2}$ bonds $(1570$ $1620 \mathrm{~cm}^{-1}$ ) and $\mathrm{C}-\mathrm{O}$ bonds $\left(1250 \mathrm{~cm}^{-1}\right)$ (Coates, 2000). The profile spectrum of mercaptan enriched carbon ink shows carbonyl, carboxyl and epoxy groups, beside the hydroxyl group derived from organic solvents present in the printing film. After coating of the electrode surface with RGO, the profile spectrum exhibits $\mathrm{C}=\mathrm{C}$ from $\mathrm{sp}^{2}$ bonds $\left(1570-1620 \mathrm{~cm}^{-1}\right)$ typical of graphene structure and $\mathrm{C}-\mathrm{O}$ bonds $\left(1250 \mathrm{~cm}^{-1}\right)$ attributed to the edge residual groups (curve II). Herein, graphene used was thermal treated $\left(\sim 500^{\circ} \mathrm{C}\right)$ in order to re-establish the disrupted $\mathrm{sp}^{2}$ bonds improving the electronic transfer and conductivity (Calvo et al., 2015). The successful of thermal reduction was confirmed by the FTIR spectra. The main functional groups, such as- $\mathrm{OH}$ stretching and $\mathrm{C}=\mathrm{O}$ vibrations, were practically disappeared in the RGO spectra as compared with the GO (Fig. S1A). Additionally, a significant improvement of the conductivity was also accomplished by electrochemical CV technique showing an increase in approximately three times the electroactive area compared with the GO modified electrode (Fig. S1B).

Fig. 2d exhibits the electrochemical profiles of RGO modified electrode. Each voltammogram represents all the consecutive 

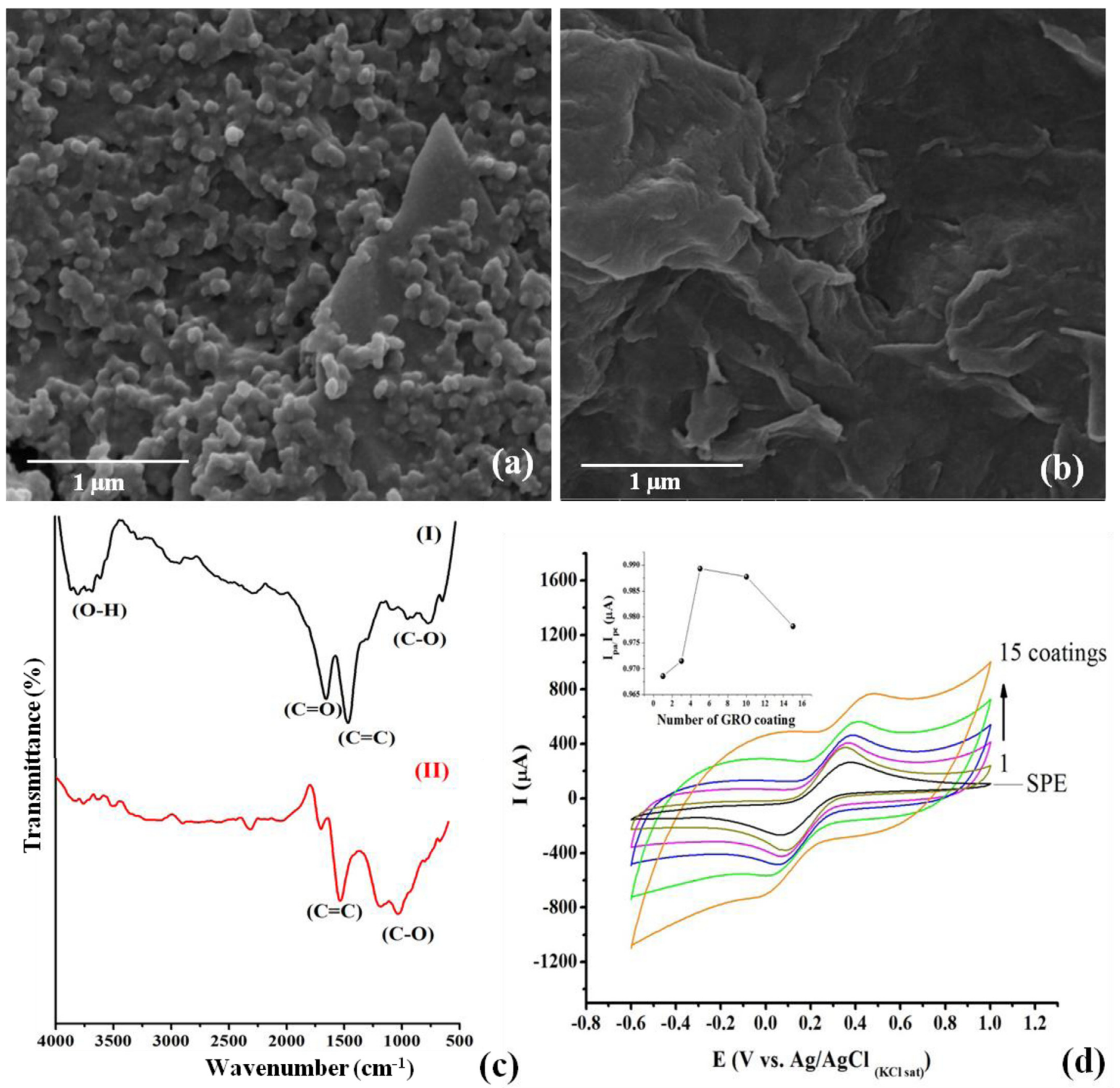

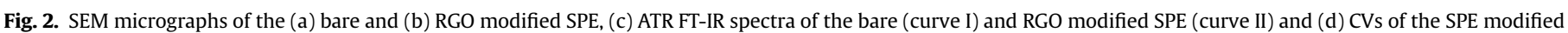
with successive RGO coatings in $\mathrm{K}_{3}\left[\mathrm{Fe}(\mathrm{CN})_{6}\right] / \mathrm{K}_{4}\left[\mathrm{Fe}(\mathrm{CN})_{6}\right]\left(0.005 \mathrm{~mol} \mathrm{~L}^{-1}\right)$ solution (inset: correlation between $\left.I_{\mathrm{pa}} / I_{\mathrm{pc}}\right)$.

incubations of SPE with RGO dispersing. According to CVs, the assembled graphene film using layer-by-layer technique by dip coatings seems form charge storage elements, or capacitive components on the electrode surface, as resulting the sum of multiples capacitors (in parallel arrangement) interposed dual graphene sheets, as reported by Sato et al. (2011). Herein, the non-faradaic component was electrochemically observed by the CVs according to the over increase of capacitive currents formed by dual alignment of graphene. As shown in Fig. 2d, it is also observed a more evident augment on the current reduction with increase in the number of RGO coatings. This effect can be attributed to the presence of functional groups (carboxyl, hydroxyl, ether) that suffered chemical reduction by thermal treatment on the GO sheets. The ratios between the anodic and cathodic peaks of the CVs ( $\mathrm{I}_{\mathrm{pa}}$ and
$\mathrm{I}_{\mathrm{pc}}$, respectively) according to number of the RGO coatings are plotted in Fig. 2d, inset. It was observed a decrease of the electrochemical reversibility after five RGO coatings.

According to Randles-Sevcik equation (Bard and Faulkner, 2001 ), there was an increase of $60 \%$ in the electroactive area of the RGO modified SPE $\left(0.147 \mathrm{~cm}^{2}\right)$ compared with the bare SPE $\left(0.09 \mathrm{~cm}^{2}\right)$, showing an improvement of conductivity, due to the higher electronic transfer.

\subsection{Characterization of the N-MIP sensor}

The choice of suitable monomers in the constructing of biomimetic sites is an important step to obtain more selective and sensible MIPs. Firstly, it was focused in a choice of a conductive 
a

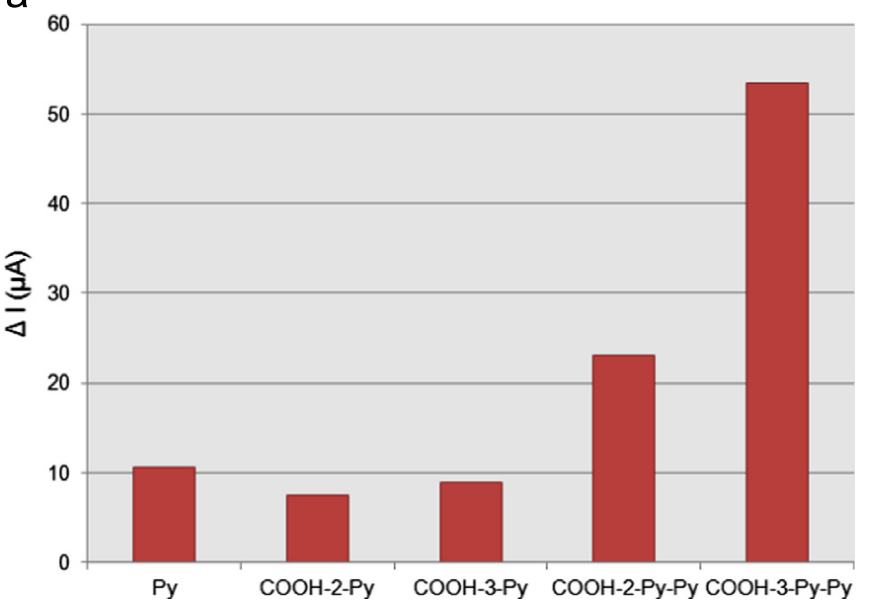

b

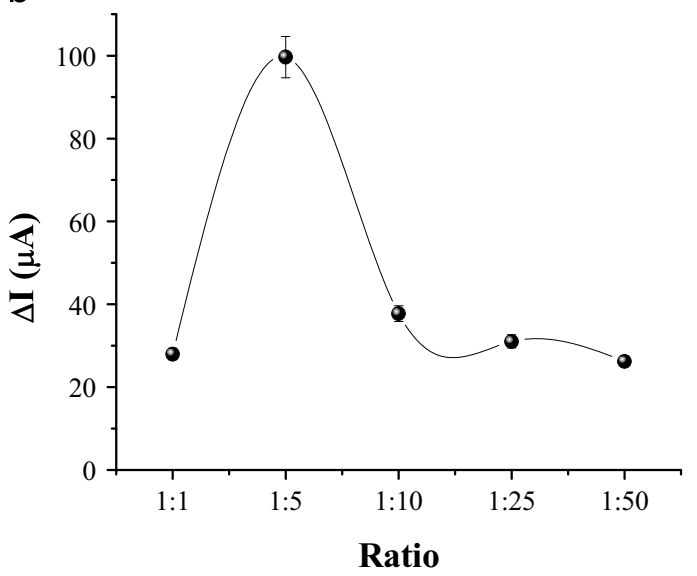

Fig. 3. (a) Influence of the combinations of the Py monomers in the constructing of the N-MIPs and (b) Py and COOH-3-Py ratio in the N-MIP electropolymerization. $\Delta I$ values obtained of CVs analyses in $\mathrm{K}_{3}\left[\mathrm{Fe}(\mathrm{CN})_{6}\right] / \mathrm{K}_{4}\left[\mathrm{Fe}(\mathrm{CN})_{6}\right]\left(0.005 \mathrm{~mol} \mathrm{~L}^{-1}\right)$ solution prepared in $\mathrm{KCl}\left(0.1 \mathrm{~mol} \mathrm{~L}^{-1}\right)$. All measurements were performed in triplicate.

polymer in order to reach a maximal electron transfer; secondly, the use of organic polymers containing functional groups (carboxyl) in order to obtain more reactive biomimetic sites of the cTnT. In this work, the Py was tested to be copolymerized with $\mathrm{COOH}-3-\mathrm{Py}$ and $\mathrm{COOH}-2-\mathrm{Py}$. The selection of the most selective and sensible N-MIP was carried out through the difference of current values $(\mathrm{I} \Delta)$ of the analytical response after incubation with cTnT $\left(0.5 \mathrm{ng} \mathrm{mL}^{-1}\right)$. The results showed that the $\mathrm{COOH}-3-\mathrm{Py}$ monomer was the best to form the biomimetic conductive copolymer (Fig. 3a). In 3 position at monomeric ring linked to the carboxylic group allows to promote more interactions between reactive sites with cTnT, since the interaction these $\mathrm{COOH}-3-\mathrm{Py}$ monomers in the electropolymerization processes at specific potential occur through oxidative coupling at the 2 and 5 positions of the Py ring (Tighilt et al., 2011; Janmanee et al., 2012). Contrarily, the $\mathrm{COOH}-2-\mathrm{Py}-\mathrm{Py}$ was likely to be less appropriate due to position of functional groups that disfavors the formation of the polymer chain and resulting in a steric hindrance regarding the cTnT interactions. Additionally, the cTnT in the electropolymerization solution is found in the protonated state, contributing for its interaction with the carboxylic groups of the polymeric chain.

The affinity of the molecule template with the monomers influences the formation of template cavities and binding properties of the N-MIP sensor. Thus, the ratio of the Py and COOH-3-Py in relation to cTnT in the pre-assembling solution was optimized. The current responses obtained after rebinding assay with cTnT a

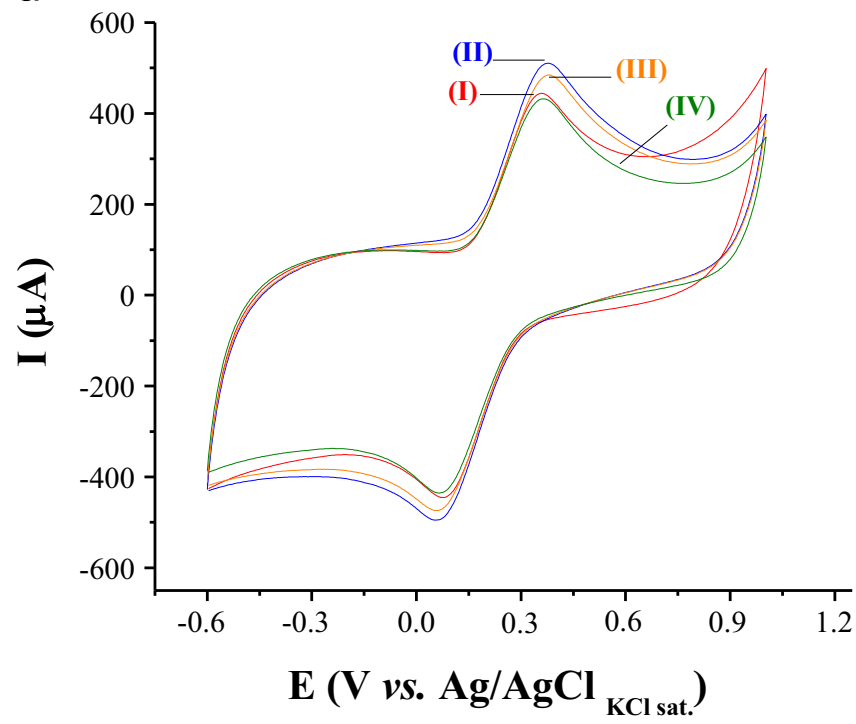

b

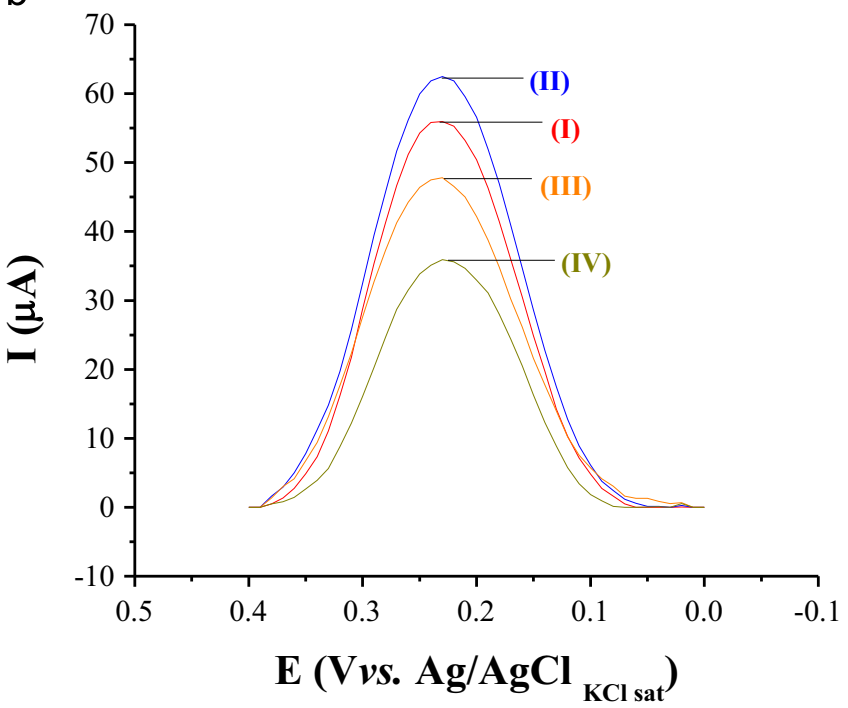

Fig. 4. Electrochemical profile of the stepwise of constructing of the N-MIP sensor by (a) CV and (b) DPV techniques: (I) RGO modified SPE; (II) after electropolymerization of the Py, $\mathrm{COOH}-3-\mathrm{Py}$ and $\mathrm{CTnT}$; (III) after removal of the cTnT and (IV) rebinding with cTnT $\left(0.5 \mathrm{ng} \mathrm{mL}^{-1}\right)$. Measurements performed in $\mathrm{K}_{3}\left[\mathrm{Fe}(\mathrm{CN})_{6}\right]$ $\mathrm{K}_{4}\left[\mathrm{Fe}(\mathrm{CN})_{6}\right]\left(0.005 \mathrm{~mol} \mathrm{~L}^{-1}\right)$ solution prepared in $\mathrm{KCl}\left(0.1 \mathrm{~mol} \mathrm{~L}^{-1}\right)$.

showed a maximal value when the Py and $\mathrm{COOH}-3-\mathrm{Py}$ was found at $1: 5$ ratio, respectively (Fig. $3 b$ ). This result indicates that the cTnT probably was captured mainly by the carboxylic groups of copolymeric matrix. However, other functional groups that appear in oxidization process of the PPy, such as $-\mathrm{NH}$ groups may react with the cTnT template to obtain the recognition sites (Ratautaite et al., 2015). The cTnT and the N-MIP sensor interactions based on Py and $\mathrm{COOH}-3-P y$ film is associated to non-covalent interactions, such as hydrogen bonds and electrostatics interactions (Gupta et al., 2013), as have shown in Fig. 1.

The electrochemical stepwise of the N-MIP construction were investigated by CV and DPV techniques, Fig. 4a and b, respectively. The cyclic voltammograms of the RGO modified SPE in Fig. 4a (curve I) showed an increase of redox peaks and reduction in the potential peak-to-peak separation $(\Delta E)$ of $0.25 \mathrm{~V}$ when compared with bare SPE $(0.34 \mathrm{~V})$. It was associated to the high conductivity and excellent electrocatalytic activity of RGO film on SPE surface. After electropolymerization of the Py and cTnT on RGO surface, it was observed an increase of redox peaks in the CV (curve II). The 
electroactive area (Bard and Faulkner, 2001) calculated to SPE with the cTnT electropolymerized in the copolymeric matrix was $0.168 \mathrm{~cm}^{2}$. This value exhibits a slight increase when compared with the RGO modified SPE, showing that the conductive copolymer of Py was assembled around the cTnT template and was uniformly deposited onto the nanostructured surface. A decrease of the redox peaks was observed after removal of the cTnT with oxalic acid (curve III). This fact can be attributed to the hydrolysis of the imine and amide bonds formed between the protein template and the copolymer matrix, providing most efficient sites for rebinding of the biomolecule (Shiomi et al., 2005). The rebinding test of the as-prepared N-MIP with cTnT $\left(0.5 \mathrm{ng} \mathrm{mL}^{-1}\right)$ showed a reduction in the peak current. The filling out of the N-MIPs cavities with cTnT blocked the electron transfer on electrode surface (curve IV). The results obtained by DPV in Fig. 4b are in accordance to those obtained with CVs studies. When the N-MIP was regenerated with an oxalic acid solution the redox peaks was returned to its original value, indicating an efficient removal of cTnT in the biomimetic sites (Fig. S2).

\subsection{Experimental conditions}

The thickness film is an important factor that affects the recognition ability in N-MIP based on electropolymerization process. It can be affected by electropolymerization parameters such as monomer concentration, cycles of electropolymerization, scan rate and other. Optimal experimental parameters, were established through the $\Delta I$ value after rebinding with cTnT $\left(0.5 \mathrm{ng} \mathrm{mL}^{-1}\right)$ observed in the CVs. Firstly, the influence of the number of cycles of electropolymerization $(5,10,20,30$ and 40$)$ of the Py monomers on the N-MIP was evaluated. The results demonstrated a maximal current response at 20 cycles (Fig. S3a). After 30 cycles, the signals showed a decrease. This can be ascribed to the film thickness of the copolymeric matrix that grows up with the number of the cycles and leads to form the film with less accessible printed sites.

A suitable removal of the template in the N-MIP contributes to produce structurally-related template in the polymeric matrix. Herein, the cTnT electropolymerized in the Py copolymer on SPE surface was incubated during $1,2,4,6,8$ and $12 \mathrm{~h}$ with an oxalic acid solution at $4{ }^{\circ} \mathrm{C}$ in a moist chamber. The $\Delta I$ obtained of the CVs measurements reached a plateau at $12 \mathrm{~h}$ of the removal time (Fig. S3b). This maximal time may be attributed to complex structures of the cTnT printed in the copolymeric film for removal and form the cTnT imprinted sites.

The optimal incubation time was investigated in order to establish the molecular recognition properties of the N-MIP sensor. The sites at the sensor interface were incubated with cTnT solution ( $\left.0.5 \mathrm{ng} \mathrm{mL} \mathrm{mL}^{-1}\right)$ during different time $(5,15,30,45$ and $60 \mathrm{~min})$ at room temperature. The response showed a proportionally increase in the $\Delta I$ with the incubation time (Fig. S3c). The N-MIP reached a maximal response at $30 \mathrm{~min}$.

\subsection{Analytical performance of the N-MIP sensor}

The analytical performance of the N-MIP and N-NIP sensor was evaluated by submitting different SPEs to specific concentrations of the cTnT diluted in phosphate saline buffer ( $\mathrm{pH} 7.4$, $0.01 \mathrm{~mol} \mathrm{~L}^{-1}$ ), as shown in Fig. 5. The response of the N-MIP sensor was obtained by using the percentual decrease of current $(\mathrm{I} \Delta \%)$ of the DPVs measurements in $\mathrm{K}_{3}\left[\mathrm{Fe}(\mathrm{CN})_{6}\right] / \mathrm{K}_{4}\left[\mathrm{Fe}(\mathrm{CN})_{6}\right]$ $\left(0.005 \mathrm{~mol} \mathrm{~L}^{-1}\right)$ after incubation with cTnT. N-NIP sensor, without the presence of the cTnT in the copolymeric matrix, was investigated with a control study. The N-MIP sensor (curve I) exhibited a hyperbolic response with a proportional increase of the I $\Delta \%$ in relation to cTnT concentrations until reached a plateau at $0.5 \mathrm{ng} \mathrm{mL}^{-1}$. These dates were recorded through of the

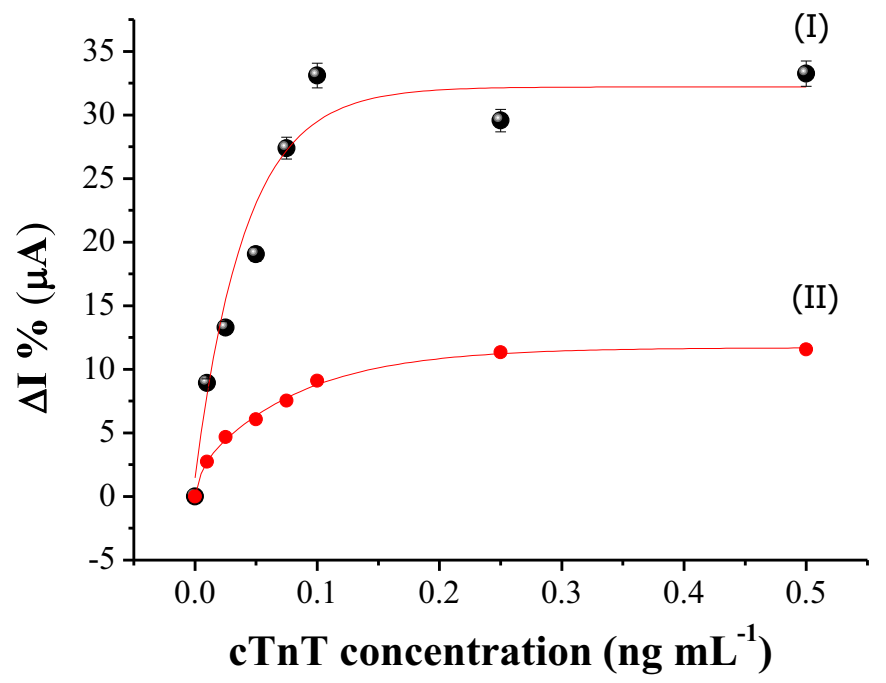

Fig. 5. Analytical curve of the (curve I) N-MIP and (curve II) N-NIP for different cTnT concentrations $\left(0.01 ; 0.025 ; 0.05 ; 0.075 ; 0.1 ; 0.25\right.$ and $0.5 \mathrm{ng} \mathrm{mL}^{-1}$ ). Measurements performed in $\mathrm{K}_{3}\left[\mathrm{Fe}(\mathrm{CN})_{6}\right] / \mathrm{K}_{4}\left[\mathrm{Fe}(\mathrm{CN})_{6}\right]\left(0.005 \mathrm{~mol} \mathrm{~L}^{-1}\right)$ solution prepared in $\mathrm{KCl}\left(0.1 \mathrm{~mol} \mathrm{~L}^{-1}\right)$.

monitoring of the blocking of the electron transfer at sensor interface due to the rebinding of the cTnT in the printed sites of the $\mathrm{N}$-MIP film. A linear relationship between the $\Delta \mathrm{I} \%$ and cTnT concentrations was obtained in the range from 0.01 to $0.1 \mathrm{ng} \mathrm{mL}^{-1}$, which exhibited the following linear regression equation: $\Delta I \%=$ $271.45^{*} C_{\mathrm{CTnT}}+9.24$, with a correlation coefficient of 0.9953 $(p<0.0001, n=5)$ with a low relative error ( $« 1 \%)$.

The electrochemical performance of the N-NIP (curve II) showed a decrease in the $\Delta I \%$ values when compared to the N-MIP (curve I) response. It is attributed to the lower affinity of the cTnT in the N-NIP film , confirming that the interaction cTnT with Py copolymeric film is controlled by the printed sites. The limit of detection (LOD) of the N-MIP was determined as 3.3 RSD blank $/ \mathrm{b}$, where RSD blank is regression residual standard deviation (RSD) of the blank and $\mathrm{b}$ is the slope calculated from analytical curve (Long and Winefordner, 1983). Under conditions, the LOD was estimated to be $0.006 \mathrm{ng} \mathrm{mL}^{-1}$. The proposed N-MIP showed a good sensibility for detection of the cTnT with a higher sensitivity than Moreira et al. (2011) by using a carbon-nanotube-MIP. Although Karimian et al. (2013) has reported an ultrasensitive cTnT MIP by employing the poly-o-phenylenediamine polymer with similar LOD achieved in this work, their biomimetic sensor consisted of a conventional gold electrode, still requiring progress to become a point-of-care testing. As compared with cTnT immunosensor using cTnT monoclonal antibodies (Dutra et al., 2007; Jacobs et al., 2014; Silva et al., 2013), this N-MIP exhibited a comparable linear range and the LOD $\left(0.006 \mathrm{ng} \mathrm{mL}^{-1}\right)$ was found in same order of magnitude.

The repeatability of the N-MIP in real samples was performed by replicate measurements of a single electrode in response to the $0.5 \mathrm{ng} \mathrm{mL} \mathrm{mL}^{-1}$ cTnT. A good repeatability was found with a RSD value of $3.5 \%$ for 10 successive determinations. The N-MIP showed a good reproducibility with a RSD of $4.1 \%$ for ten different sensors after rebinding tests with $0.5 \mathrm{ng} \mathrm{\textrm {mL } ^ { - 1 }}$ cTnT. The long-term stability test of the N-MIP was conducted by measuring the average electrochemical responses of seven sensors, stored in a moist chamber at $4{ }^{\circ} \mathrm{C}$, each day during a week. The current results (Fig. S4), after incubation with cTnT, revealed that $91.48 \%$ of the analytical response was preserved during a week of storage, indicating a good stability.

The binding isotherm predicts the affinity of N-MIPs based on the relationship between the printed sites and the analyte 
concentration generated of equilibrium rebinding studies. Herein, Langmuir isotherm was used as a model to calculate the $K_{D}$, a dissociation constant based on concentration of template providing half of the maximum response of the N-MIP response (Moreira et al., 2014). According to the model, the $K_{D}$ of the N-MIP and N-NIP sensor was $7.310^{-13} \mathrm{~mol} \mathrm{~L}^{-1}$ and $11.610^{-13} \mathrm{~mol} \mathrm{~L}^{-1}$, respectively. The $K_{\mathrm{D}}$ calculated of the N-MIP was $40 \%$ lower when compared as N-NIP, reflecting a high affinity of the biomimetic sites to low cTnT concentrations. The constant of the N-MIP is comparable to that of conventional antibodies that exhibits $K_{\mathrm{D}}$ in the range of $10^{-7}-10^{-9} \mathrm{~mol} \mathrm{~L}^{-1}$ (Chen et al., 2014).

\subsection{Determination of the cTnT in serum samples}

Serum samples of infarcted patients were analyzed to evaluate the performance of the N-MIP sensor. The amount of cTnT in the serum samples was previously measured by a Roche Elecsys 2010 Immunoassay Analyzer (Roche Diagnostics) that is based on the ECLIA method. The assays were carried out in triplicate by incubation of the N-MIP sensor during 30 min with different serum samples diluted in phosphate buffer saline solution $\left(0.01 \mathrm{~mol} \mathrm{~L}^{-1}\right.$, $\mathrm{pH}$ 7.4). The relationship between the $\Delta I \%$ values obtained of DPV measurements and the cTnT serum concentrations can be analyzed in Fig. 6a. The linear regression equation for analytical response of the N-MIP for serum samples was $\Delta I \%=$

a

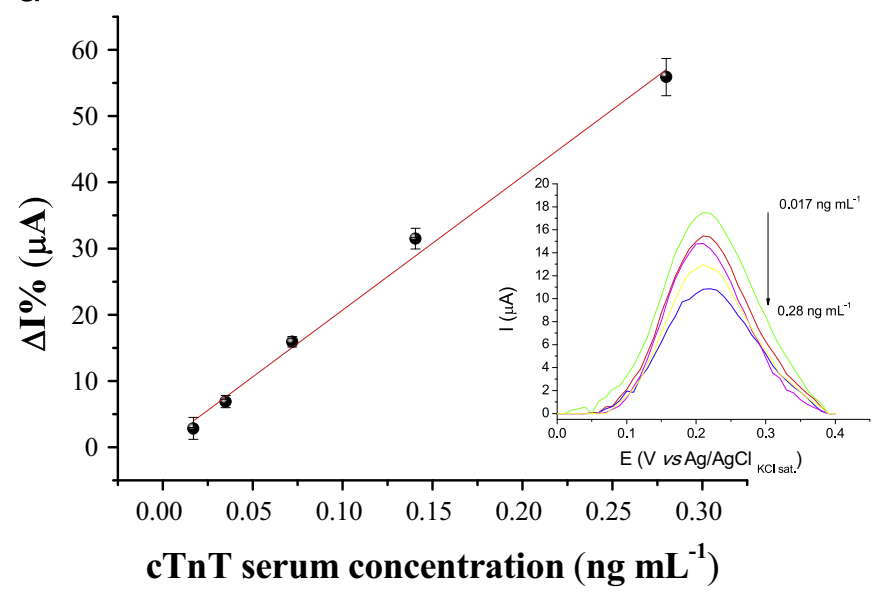

b

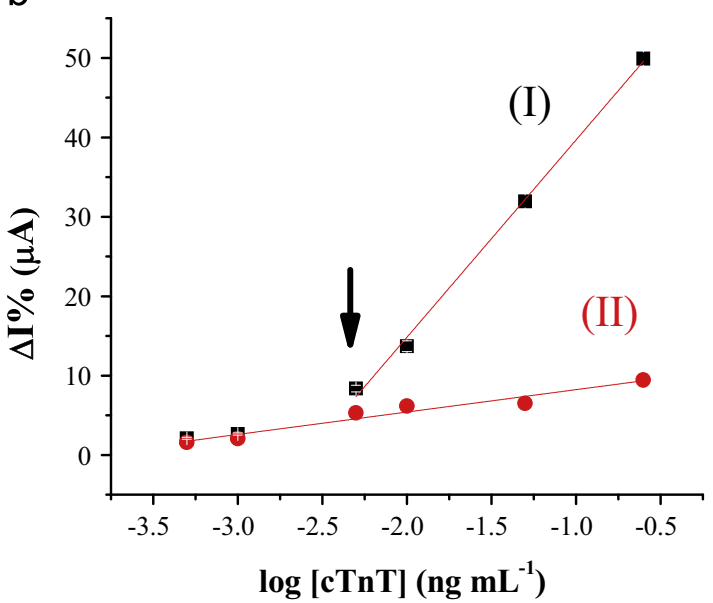

Fig. 6. (a) N-MIP response for cTnT concentration in serum samples (inset: DPVs of the N-MIP sensor in $\mathrm{K}_{3}\left[\mathrm{Fe}(\mathrm{CN})_{6}\right] / \mathrm{K}_{4}\left[\mathrm{Fe}(\mathrm{CN})_{6}\right]\left(0.005 \mathrm{~mol} \mathrm{~L}^{-1}\right)$ solution prepared in $\left.\mathrm{KCl}\left(0.1 \mathrm{~mol} \mathrm{~L}^{-1}\right)\right)$ and (b) influence of the matrix effect over N-MIP sensor for a pool of sera of (curve I) myocardial infarcted and (curve II) non-myocardial infarcted subjects. Error bars represent the standard deviations for three replicates.
Table 1

Recovery values for cTnT concentrations ( $\mathrm{ng} \mathrm{mL}^{-1}$ ) in serum samples measured by the N-MIP sensor and gold-standard method (ECLIA assay).

\begin{tabular}{llc}
\hline ECLIA method & N-MIP sensor & Recovery (\%) \\
\hline 0.017 & 0.021 & 115 \\
0.035 & 0.039 & 111 \\
0.072 & 0.079 & 109 \\
0.141 & 0.157 & 111 \\
0.280 & 0.271 & 97 \\
\hline
\end{tabular}

$202^{*} C_{\mathrm{cTnT}}+0.609(r=0.993, p<0.0001, n=5)$. A proportional decrease in the peak current of the DPVs with cTnT concentrations in real samples was obtained (Fig. 6a, inset). This suppression of the response in the voltammograms can be ascribed to the specific binding of analyte in the sites of the N-MIP. The accuracy of N-MIP in relation to the ECLIA method was evaluated by performing analytical recovery experiments. The recoveries were in the range from $96 \%$ to $115 \%$ (Table 1 - Supplementary data). According to Student $t$-test, the methods are similar at a 95\% confidence level, showing that good correlation with the ECLIA method and the accuracy of the N-MIP sensor, with an average error of approximately $10 \%$.

The selectivity of the N-MIP was tested from a complex matrix of a pool of sera. The pool was obtained by mixing 10 sera, in which a part thereof has been spiked to a concentration of $0.5 \mathrm{ng} \mathrm{mL}^{-1}$ cTnT. The analytical responses to cTnT were performed against the serial dilutions of the samples for both, the spiked and control sera. According to Fig. 6b, it was still possible to observe significant differences between positive samples (curve I) and negative (curve II) up to the fourth serial dilution, at $1 / 100$ dilution as highlighted by arrow, corresponding to the concentration of $0.005 \mathrm{ng} \mathrm{mL}^{-1}$ cTnT. This value is consistent with the LOD obtained, showing that the proposed N-MIP has capacity to differentiate the cTnT in complex matrices of serum samples being adequate to a point-of-care testing for AMI.

\section{Conclusions}

A conductive N-MIP by direct electropolymerization of cTnT biomimetic on the electrode surface was successful developed. The RGO on the SPE was strategically explored to form more porous and larger surface allowing N-MIPs 3D structures, and improving the sensitivity. Additionally, the use of organic and conducting polymers seems to be a contributing factor to increase the performance. It was found a binding constant similar to those obtained from natural biomolecules. Finally, it was developed a biomimetic sensor integrating a low cost and practical technology of the SPE with a high stability, and powerful for AMI detection.

\section{Acknowledgments}

This work was supported by the National Council of Technological and Scientific Development (CNPq/Brazil) and FACEPE/ Brazil, the Pernambuco state research foundations. Bárbara V.M. Silva thanks to Coordination for the Improvement of Higher Education Personnel (CAPES), Brazil foundation, for the scholarship during this work.

\section{Appendix A. Supplementary material}

Supplementary data associated with this article can be found in the online version at http://dx.doi.org/10.1016/j.bios.2015.10.068. 


\section{References}

Alonso-Lomillo, M.A., Domínguez-Renedo, O., Matos, P., Arcos-Martínez, M.J., 2010 Anal. Chim. Acta. 665 (1), 26-31.

Bard, A.J., Faulkner, L.R., 2001. Electrochemical Methods: Fundamentals and Applications. John Wiley \& Sons, New York.

Cabral-Miranda, G., Gidlund, M., Sales, M.G.F., 2014. J. Mater. Chem. B 2, 3087-3095.

Calvo, A.S., Botas, C., Martín-Yerga, D., Álvarez, P., Menéndez, R., Costa-García, A., 2015. J. Electrochem. Soc. 162 (10), B282-B290.

Chen, H., Kong, J., Yuan, D., Fu, G., 2014. Biosens. Bioelectron. 53, 5-11.

Cinti, S., Arduini, F., Carbone, M., Sansone, L., Cacciotti, I., Moscone, D., Palleschi, G., 2015. Electroanal 27, 2230-2238.

Coates, J., 2000. Interpretation of infrared spectra, a practical approach. In: Meyers, R.A. (Ed.), Encyclopedia of Analytical Chemistry. John Wiley \& Sons, Chichester, pp. 10815-10837.

Cui, Z., Guo, C.X., Yuan, W., Li, C.M., 2012. Phys. Chem. 14, 12823-12828.

Ding, X., Heiden, P.A., 2014. Macromol. Mater. Eng. 299, 268-282.

Dutra, R.F., Mendes, R.K., Lins da Silva, V., Kubota, L.T., 2007. J. Pharm. Biomed. Anal. $43,1744-1750$.

Granado, V.L.V., Gutiérrez-Capitán, M., Fernández-Sánchez, C., Gomes, M.T.S.R., Rudnitskaya, A., Jimenez-Jorquera, C., 2014. Anal. Chim. Acta. 809, 141-147.

Gupta, V.K., Yola, M.L., Özaltın, N., Atar, N., Üstündağ, Z., Uzun, L., 2013. Electrochim. Acta $112,37-43$.

Hong, C.-C., Chen, C.-P., Horng, J.-C., Chen, S.-Y., 2013. Biosens. Bioelectron. 50, $425-430$.

Hummer Jr., W.S., Offerman, R.E., 1958. J. Am. Chem. Soc. 80 (6) 1339-1339.

Huynh, T.P., Pietrzyk-Le, A., K.C., C. Bikram, Noworyta, K.R., Sobczak, J.W., Sharma, P. S., D’Souza, F., Kutner, W., 2013. Biosens. Bioelectron. 41, 634-641.

Jacobs, M., Panneer Selvam, a, Craven, J.E., Prasad, S., 2014. J. Lab. Autom. 19, $546-554$.
Janmanee, R., Baba, A., Phanichphant, S., Sriwichai, S., Shinbo, K., Kato, K., Kaneko, F., 2012. ACS Appl. Mater. Interfaces 4, 4270-4275.

Karimian, N., Vagin, M., Zavar, M.H.A., Chamsaz, M., Turner, A.P.F., Tiwari, A., 2013. Biosens. Bioelectron. 50, 492-498.

Kim, J.M., Yang, L.C., Park, J.Y., 2015. Sens. Actuators B -Chem. 206, 50-55.

Long, G.L., Winefordner, J.D., 1983. Anal. Chem. 55, 713A-724A.

Moreira, F.T.C., Dutra, R.A.F., Noronha, J.P.C., Cunha, A.L., Sales, M.G.F., 2011. Biosens. Bioelectron. 28, 243-250.

Moreira, F.T.C., Sharma, S., Dutra, R.A.F., Noronha, J.P.C., Cass, A.E.G., Sales, M.G.F., 2014. Sens. Actuators B -Chem. 196, 123-132.

Nezhadali, A., Pirayesh, S., Shadmehri, R., 2013. Sens. Actuators B -Chem. 185, $17-23$.

Prasad, B.B., Pandey, I., Srivastava, A., Kumar, D., Tiwari, M.P., 2013. Sens. Actuators B -Chem. 176, 863-874.

Ratautaite, V., Plausinaitis, D., Baleviciute, I., Mikoliunaite, L., Ramanaviciene, A., Ramanavicius, A., 2015. Sens. Actuators B -Chem. 212, 63-71.

Rossetti, C., Qader, A.A., 2014. Anal. Chem. 86, 12291-12298.

Sato, J., Takasu, Y., Fukuda, K., Sugimoto, W., 2011. Chem. Lett. 40 (1), 44-45.

Shiomi, T., Matsui, M., Mizukami, F., Sakaguchi, K., 2005. Biomaterials 26, 5564-5571.

Silva, B.V.M., Cavalcanti, I.T., Silva, M.M.S., Dutra, R.F., 2013. Talanta 117, 431-437. Soleimani, M., Afshar, M.G., Shafaat, A., Crespo, G.A., 2013. Electroanal 25, 1159-1168.

Thygesen, K., Alpert, J.S., Jaffe, A.S., Simoons, M.L., Chaitman, B.R., White, H.D., 2012. Circulation 126, 2020-2035.

Tighilt, F.-Z., Subramanian, P., Belhaneche-Bensemra, N., Boukherroub, R., Gabouze, N., Sam, S., Szunerits, S., 2011. Analyst 136, 4211-4216.

Xue, C., Wang, X., Zhu, W., Han, Q., Zhu, C., Hong, J., Zhou, X., Jiang, H., 2014. Sens, Actuators B -Chem. 196, 57-63. 